\begin{tabular}{|l|l|l|}
\hline \multicolumn{2}{|c|}{ PublisherInfo } \\
\hline \hline PublisherName & $:$ & BioMed Central \\
\hline \hline PublisherLocation & $:$ & London \\
\hline \hline PublisherImprintName & $:$ & BioMed Central \\
\hline \hline
\end{tabular}

\title{
IL-4 gene therapy in arthritis
}

\begin{tabular}{|l|l|l||}
\hline \multicolumn{2}{|c|}{ ArticleInfo } \\
\hline \hline ArticleID & $:$ & 210 \\
\hline \hline ArticleDOI & $:$ & $10.1186 /$ ar-2000-66775 \\
\hline \hline ArticleCitationID & $:$ & 66775 \\
\hline \hline ArticleSequenceNumber & $:$ & 167 \\
\hline \hline ArticleCategory & $:$ & Paper Report \\
\hline \hline ArticleFirstPage & $:$ & 1 \\
\hline \hline ArticleLastPage & $:$ & 3 \\
\hline \hline & & RegistrationDate : 2000-1-20 \\
\hline ArticleHistory & $:$ & OnlineDate \\
\hline ArticleCopyright & $:$ & Current Science Ltd2000-1-20 \\
\hline \hline ArticleGrants & $:$ & \\
\hline \hline ArticleContext & $:$ & 130753311 \\
\hline \hline
\end{tabular}


Aff1 Oueen Mary and Westfield College, London, UK

\section{Keywords}

Adjuvant arthritis, gene therapy, IL-4, retrovirus, rheumatoid arthritis

\section{Context}

In rheumatoid arthritis small amounts of T-cell cytokines are detected in joints, and those present are derived from $\mathrm{T}$ helper (Th) 1 cells. Th2-derived products are not detected and this Th1/Th2 imbalance has been postulated as a mechanism in the disease process. Results from animal studies have suggested that Th2 cytokines may have therapeutic benefits. In this study a retroviral vector encoding IL-4 was delivered by intra-articular injection into an inflamed joint of a rat arthritis model. IL-4 expression was monitored and the therapeutic effect in adjuvant-induced arthritis assessed. To examine the expression and therapeutic effect of IL-4 expressed from a retroviral vector following intra-articular delivery to inflamed joints in an adjuvant-induced arthritis model.

\section{Significant findings}

In vitro synoviocyte transduction demonstrated that IL-4 expression increased with higher retroviral titres, and with time over the 10 day period examined. In vivo transduction of the inflamed joints demonstrated that endogenous expression of IL-4 during the course of inflammation increased from less than $0.2 \mathrm{ng} / \mathrm{g}$ tissue at day 0 to approximately $0.7 \mathrm{ng} / \mathrm{g}$ tissue at day 20 . This baseline production was similar for both non-transduced and DA-?Gal-transduced joints (day 12), indicating that vector itself did not induce IL-4 expression. Following DA-IL-4 transduction on day 12 expression of IL-4 was determined on days 15 and 20 . At both timepoints IL-4 expression was significantly elevated above baseline at approximately 0.05 and $2 \mathrm{ng} / \mathrm{g}$ tissue respectively. IL-4 levels in serum also increased in excess of three-fold by day 20 and levels in the contralateral joint increased from baseline levels on day 15 to levels equivalent to those in the transduced joint on day 20. RT-PCR demonstrated that IL-4 mRNA was restricted to DA-IL-4-transduced joints at days 15 and 20 with no mRNA detected in DA?Gal-injected, or contralateral joints, at these times. IFN-? remained undetected in the joints at all times. In terms of therapeutic effect, joint swelling in DA-IL-4-treated paws was decreased compared to joints that received the control vector (and contralateral joints). Radiographs also showed decreased joint destruction in DA-IL-4-treated joints versus contralateral joints. 


\section{Comments}

The expression of interleukin (IL)-4 achieved following intra-articular transduction is impressive, with elevated levels observed locally, in serum, and in the contralateral joint. Systemic expression of IL-4 is contrary to the local expression anticipated in this study. However, the fact that systemic levels of IL-4 can be achieved following retroviral delivery to a single joint is of great interest and encouraging for the future application of retroviral vectors by intra-articular injection. The anti-inflammatory effects observed in this study are in contrast to findings in mouse collagen-induced arthritis, where intraarticular delivery of IL-4 by an adenoviral vector exacerbated inflammation (Paper report). There are important differences between these two studies. Firstly, retroviral injection did not induce the inflammatory response reported with the adenovirus. Secondly, higher levels of IL-4 expression were achieved by retroviral transduction, as detection of IL-4 in the serum was possible only in this study.

\section{Methods}

Retroviral constructs were prepared that encode rat IL-4 (DA-IL-4) and LacZ (DA-?Gal). Human fibroblast-like synoviocytes were isolated and transduced in vitro in order to characterise IL-4 expression from DA-IL-4. Adjuvant-induced arthritis was elicited in Lewis rats by injection of complete Freund?s adjuvant into the tail at day 0. Development of arthritis was monitored by water displacement plethysmography, with paw swelling obvious between days 10 and 12 . On day 12 high titre retrovirus (DA-IL-4 or DA-?Gal) was administered by intra-articular injection to the right ankle. Expression of IL-4 and interferon (IFN)-? in joints was measured in the supernatant derived from homogenised ankle joint tissue using ELISA. Reverse transcriptase polymerase chain reaction (RT-PCR) was performed for deduction of IL-4 mRNA in joint tissue extracts.

\section{References}

1. Boyle DL, Nyugen KHY, Zhuang S, Shi Y, McCormack JE, Chada S, Firestein GS: Intra-articular IL-4 therapy in arthritis: anti-inflammatory effect and enhanced Th2 activity. Gene Ther. 2000, 6:

1911-1918.

This PDF file was created after publication. 